Hispania, 2014, vol. LXXIV, nº. 247, mayo-agosto, págs. 465-494

ISSN: 0018-2141, e-ISSN: 1988-8368, doi: 10.3989/hispania.2014.015

\title{
Financiación y gestión de la repatriación de inmigrantes españoles entre 1907 y $1936^{*}$
}

RESUMEN: En 1907 se aprobó la primera Ley de Emigración Española, cuyo artículo 46 establecía la obligatoriedad por parte de las compañias navieras de repatriar, con pasajes a mitad de precio, a un máximo del veinte por ciento de los emigrantes que hubieran trasladado durante el trimestre anterior. El presente estudio explica el modo en que se efectuaron dichas repatriaciones, los supuestos legales y económicos que las hicieron posibles y los actores institucionales que intervinieron en el proceso. Para ello se ha consultado la correspondencia del Ministerio de Estado con la red de consulados y embajadas emplazada en países receptores de inmigración, así como con la naviera española más importante y con algunas instituciones privadas que asistían a los inmigrantes. El análisis de los cambios legales y organizativos habidos en el período comprendido entre 1907 y 1936 - lapso cronológico contemplado- se presenta en tres fases: 1907-1924, 1924-1931 y 1931-1936. Las repatriaciones se concentraron en momentos de crisis económicas, cuando el desempleo y la falta de recursos afectaron fuertemente a los mercados de trabajo de las comunidades migratorias. La vaguedad con que fue redactado del texto legal y el déficit crónico de recursos hicieron de la repatriación un recurso poco eficiente y escaso.

\section{PALABRAS CLAVE: Emigración; repatriación; crisis económica; Espa- ña; América Latina.}

* Se han empleado las siguientes abreviaturas: AGAE, CEM (Archivo General de la Administración Española, Consulado de España en México), AGAE, EEM (Embajada de España en México) y AGAE, AE (Asuntos Exteriores); AMAE (Archivo del Ministerio de Asuntos Exteriores de España); MSBE (Memorias de la Sociedad de Beneficencia Española de México). 
Financing and Management of the Spanish Inmigrants Repatriation between 1907 and 1936

ABSTRACT: The first Spanish Migration Law was approved in 1907. The article forty six of this law dealt with the subsidized repatriation of those who could not stay in the immigration countries because of the lack of means of support. According to this law, the shipping companies had to provide a half passage up to twenty per cent of the passengers who were shipped to the Americas during the previous three months. In this paper we explain the way in which these repatriations were carried out, and the official arrangements and economic measures taken during the period between 1907 and 1936. We have analyzed the official communication between the Spanish foreign affairs bureau and its network of consulates and embassies in the American countries, as well as with the main Spanish shipping company and, finally, with some of the main associations of the Spanish communities. Three periods have been established to analyze the legal and financial changes in the repatriation process: 1907-1924, 1924-1931 and 1931-1936. We found that most of the repatriation requests were concentrated during economic crisis when the unemployment affected to the Spanish workers. The ambiguity of the law as well as the lack of financial funds made the repatriation an inefficient and scarce resource to bring people back to their homeland.

KEY WORDS: Migration; Repatriation; Economic crisis; Spain; Latin America.

\section{INTRODUCCIÓN}

A fines del año 1907 fue aprobada en España la Ley de Emigración, primera ocasión en que se reguló el fenómeno migratorio de un modo integral, aunque el nuevo código recogía una enorme cantidad de decretos y órdenes en materia migratoria promulgados de forma dispersa desde mediados del siglo XIX. Con esta legislación el Estado español mostraba su intención de intervenir en el proceso migratorio a través de ciertas medidas de corte paternalista, como la obligación de las autoridades portuarias y consulares de proteger a los emigrantes frente a los abusos de enganchadores y consignatarios ${ }^{1}$.

Una de las innovaciones incluidas en este primer estatuto general migratorio fue la imposición a las compañías navieras transatlánticas de repatriar, con pasajes a mitad de precio, hasta una quinta parte de los inmigrantes llevados a

1 PÉREZ-PRENDES, 1992: 86-88. Un enganchador es un agente comisionado por las empresas navieras o gobiernos receptores de emigración que recluta individuos en sus lugares de origen y lucra con ello; un consignatario es la persona que en los puertos de mar representa al armador de un buque para ocuparse de los asuntos administrativos que se relacionan con su carga y pasaje. 
un determinado país en el trimestre anterior. La cifra anual de repatriaciones dependería, de ese modo, del número total de emigrantes trasladados a ultramar en el período previo. El Estado estipulaba así el cobro de un canon indirecto a los empresarios navieros — nacionales y foráneos- involucrados en el tráfico trasatlántico de pasajeros, confiando, por otro lado, la gestión y entrega de los medios pasajes a las agencias consulares destacadas en los países receptores de inmigración ${ }^{2}$. Se puede considerar, pues, que los legisladores contemplaban, a través del artículo 46 de repatriación de inmigrantes, la posibilidad de que un cierto número de individuos experimentara dificultades insuperables en el país de acogida, ante lo cual el Estado debía encargarse de apoyarlos económicamente y protegerlos en su viaje de retorno, siempre y cuando demostraran su nacionalidad española, su honradez probada y su total falta de recursos para continuar en el país receptor ${ }^{3}$.

Retorno y repatriación no constituyen, en este estudio, conceptos sinónimos. Definimos repatriación tal y como solían utilizarlo los documentos oficiales del período, como un proceso de retorno gestionado y subvencionado por el Estado español, las asociaciones mutuales y asistenciales y las redes sociales de los inmigrantes en los lugares de recepción. Se trataba, por tanto, de un tipo de retorno de la emigración tutelado por instancias oficiales, públicas y privadas ${ }^{4}$.

En los años siguientes a la promulgación de este nuevo marco jurídico se produjo la salida más numerosa de emigrantes españoles, hasta que la Primera Guerra Mundial paralizó de forma temporal el flujo migratorio ultramarino. Este se reanudó en la década de 1920 — una vez finalizada la crisis de posguerra - pero se detuvo en los años posteriores a la crisis de 1929. La Ley de Emigración, aun con numerosas modificaciones y ajustes a las circunstancias cambiantes, continuó vigente hasta 1960. Las disposiciones respecto al artículo 46 permanecieron sin grandes alteraciones en la primera revisión importante de la legislación migratoria realizada en 1924. En 1928 se hicieron algunas precisiones, de nuevo sin modificar substancialmente el texto de 1907. Durante la Segunda República, sin embargo, se produjo un retorno masivo de inmigrantes debido a la crisis económica internacional. La reglamentación del artículo 46 experimentó entonces cambios considerables, en respuesta al fuer-

2 Ley de Emigración de 21 de diciembre de 1907, Cap. IV, art. 46. Inspección General de Emigración, 1932: 15.

3 GIL LÁZARO, 2008: 268. Las apreciaciones oficiales acerca de quiénes eran considerados sujetos potencialmente merecedores de repatriación cambiaron en el transcurso de estos años, aunque estos tres requisitos — la nacionalidad, la honradez y la falta de recursos - permanecieron constantes.

4 De este modo, a lo largo del texto el término «repatriación» se utilizará con el mismo significado que «retorno asistido», «retorno subvencionado» o «retorno tutelado» por el Estado, haciendo alusión al concepto tal y como aparece en las fuentes primarias. 
te descenso del flujo emigratorio desde España y a la repercusión que este hecho tuvo en el cálculo de los pasajes subvencionados por el Estado ${ }^{5}$. La cronología del presente trabajo se limita a las décadas que transcurren entre la puesta en marcha de la legislación migratoria y el inicio de la Guerra Civil, de forma paralela al auge y ocaso del ciclo migratorio trasatlántico. El capítulo repatriador de la ley fue utilizado por las autoridades migratorias para devolver al lugar de origen sobre todo a emigrantes económicos afectados por las crisis en los mercados de trabajo internacionales ${ }^{6}$.

En estas páginas tratamos de responder a tres preguntas: cómo se efectuaban las repatriaciones, bajo qué supuestos legales y económicos fue posible repatriar a los inmigrantes y qué actores institucionales intervinieron en el proceso. Pero antes resulta imprescindible realizar un breve balance del estado de los conocimientos existentes sobre este tema - sobre todo los de carácter cuantitativo - con el fin de evidenciar las principales carencias. Después, el análisis se divide en tres fases, en función de los cambios legales acaecidos en torno a la repatriación entre 1907 y 1936 y los principales problemas económicos afrontados. La última parte del texto se referirá a las atribuciones propias de cada una de las agencias gestoras de la repatriación de inmigrantes.

La correspondencia oficial entre las instancias migratorias estatales - Consejo Superior de Emigración, en primer lugar, e Inspección General de Emigración, con posterioridad-y los consulados españoles en Argentina, Cuba y México, constituye la principal fuente documental para observar el funcionamiento práctico de las instituciones que tramitaban y costeaban la repatriación ${ }^{7}$. De especial utilidad ha sido la comunicación habitual de disposiciones legales desde Madrid a las autoridades diplomáticas emplazadas en las capitales americanas, así como el intercambio epistolar entre los representantes diplomáticos y los demás actores involucrados: sociedades asistenciales, empresas navieras — sobre todo la Compañía Trasatlántica Española- e individuos solicitantes de un pasaje de repatriación.

5 MALUQUER DE MOTES, XXV/II (Madrid, 2007): 146.

6 El agotamiento de la corriente migratoria europea se ubica tradicionalmente en torno a 1930. Sin embargo, según J. Aróstegui, España había iniciado tarde su éxodo migratorio y también el agotamiento del mismo fue más tardío. Las consecuencias de la crisis, además, fueron menos intensas en España debido al peso que todavía tenía el sector agrario, por lo que, aunque muy debilitado, el flujo de salidas continuó hasta el inicio de la guerra en 1936. ARÓSTEGUI, 1992: 434-435.

7 Justifica la elección de estos tres países la existencia de una abundante documentación consular y también de varios estudios sobre la repatriación desde cada uno de ellos. 


\section{DATOS ESCASOS Y FRAGMENTARIOS SOBRE LA REPATRIACIÓN}

Al contrario que otros aspectos de los procesos migratorios, el retorno de los españoles - y por extensión el retorno asistido - permanece aún hoy en día poco explorado. Esto ha podido deberse, en primer lugar, a la limitación de las fuentes primarias con las cuales estudiarlo. Las estadísticas migratorias son, según J. Maluquer, «rematadamente deficientes», porque, como se sabe, la definición de emigrante se efectuaba con arreglo a criterios administrativos o socio-económicos, pero no demográficos ${ }^{8}$. Por otro lado, el esquema lineal clásico que definió a la emigración durante mucho tiempo como un proceso permanente (es decir, una secuencia de etapas irreversibles: expulsión-ajusteasimilación), condicionó también el estudio del retorno.

Sin embargo, es de sobra conocido que la emigración europea a las Américas fue un proceso circular y no lineal. B. Sánchez Alonso afirma que, en las primeras décadas del siglo XX, los retornos a Europa alcanzaron un volumen sin precedentes ${ }^{9}$, no solo por las enormes mejoras producidas en los transportes, que permitían travesías más cortas, rápidas y seguras, sino por el hecho de que la emigración se configuró como un fenómeno temporal. Las series estadísticas españolas así lo corroboran, y de igual manera se percibe dicha circularidad desde las cifras americanas $(\text { Gráfico } 1)^{10}$.

8 MALUQUER DE MOTES, XXV/II (Madrid, 2007): 132.

9 SÁNCHEZ ALONSO, 1 (Madrid, 2002): 23-24.

10 YÁÑEZ GALLARDO, 1994: 119, 131-137. Si tomamos el total de la emigración europea trasatlántica, entre los años 1899 y 1912 regresó aproximadamente un 65 por ciento de los que se fueron. En el caso español, solo 4 de cada 10 españoles fijaron definitivamente su residencia en América; entre 1882 y 1959, España cedió a América 1,8 millones de habitantes, aunque al menos 4,7 llegaran a ella en este lapso. Los estudios de F. Devoto sobre la inmigración española en Argentina confirman que algo menos de la mitad de los españoles que llegaron a este país retornaron a la Península, y alrededor de un 44 por ciento de aquellos que llegaron a Brasil tomaron también la vía del regreso. DEVOTO, 1999: 203. 
GRÁFICO I: SALIDAS, RETORNOS Y SALDO MIGRATORIO DE ESPAÑOLES A AMÉRICA, 1900-1936

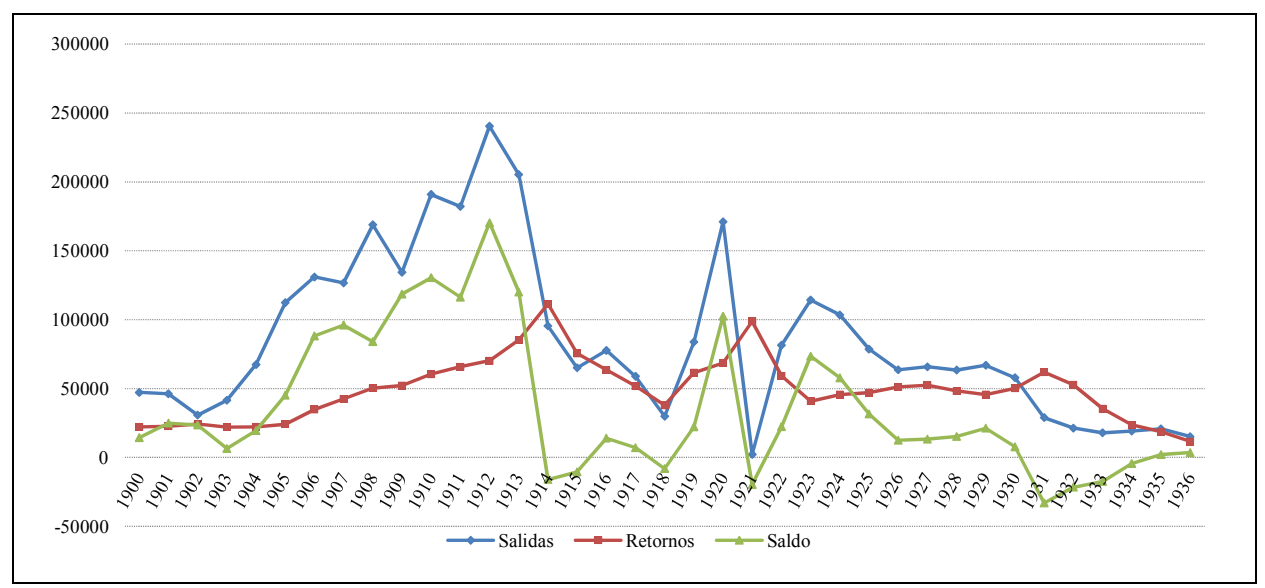

Fuente: elaborado a partir de «Series del Instituto Geográfico y Estadístico», en YÁÑEZ GALLARDO 1994:121.

Una última razón del escaso interés por el regreso de la emigración pudo derivarse de la imagen pesimista instalada entre los observadores contemporáneos de la emigración masiva, la cual asociaba el retorno a la idea del fracaso $\mathrm{y}$, en concreto, a la imposibilidad de acceder a la propiedad de la tierra, principal móvil de los campesinos para emigrar. A partir de la segunda posguerra mundial, la historiografía económica europea se dio a la tarea de contradecir esta imagen, a través de un replanteamiento de la función desempeñada por los ahorros de los retornados en los lugares de origen, con el objetivo de mostrar que las trayectorias de muchos de ellos habían sido exitosas $^{11}$.

En décadas recientes, el interés académico por el estudio de la emigración de retorno en España se ha centrado en la influencia socio-económica, política y cultural de los volvieron a sus lugares de origen y sobre todo en las regiones galaica, astur y vasca. Sin duda, los estudios más destacables en este sentido son los de J.M. Núñez Seixas, quien ha puesto de manifiesto el papel innovador de los retornados tanto en el campo como en la ciudad, y ello en aspectos como la práctica de nuevos cultivos, la urbanización, la movilización

11 DEVOTO, 2003: 77. VÁZQUEZ GONZÁLEZ, 1988: 99. Los ahorros de los retornados contribuyeron no solo a la financiación del pasaje de otras personas sino esencialmente a una mayor monetarización de las economías familiares de las clases rurales. Posibilitaron, además, la compra de tierras, la liquidación de hipotecas y evitaron el recurso al préstamo usurario. 
sociopolítica y la potenciación del asociacionismo y el cooperativismo, sobre todo en algunas áreas ${ }^{12}$.

El regreso de la emigración bajo la fórmula concreta de la repatriación (o retorno asistido) no ha sido abordado en profundidad desde la historia económica y social de las migraciones transatlánticas españolas, como tampoco han sido analizadas las causas que llevaron a los inmigrantes a solicitar esta ayuda, es decir, la intersección entre las crisis económicas - en concreto sus consecuencias en los mercados laborales migratorios-y las estrategias desarrolladas por los inmigrantes y sus comunidades para superarlas. Hacer la América, una obra esencial sobre la repatriación escrita por Marsal a fines de la década de 1960, apenas tuvo eco en la historiografía posterior, a pesar de que el autor incluye al final del libro un apéndice con un estudio cuantitativo y el perfil socio-demográfico de 272 individuos repatriados entre 1946 y $1960^{13}$. Tras este trabajo no ha habido nuevos intentos de cuantificar el retorno asisti$\mathrm{do}^{14}$.

Tres artículos publicados a principios de los años noventa abordan el problema de la repatriación. Aun cuando carecen de un análisis sistemático y no tratan de perfilar el tamaño del grupo repatriado, los tres señalan la influencia de las crisis económicas de la primera mitad del siglo XX en el deterioro de las condiciones laborales de los inmigrantes. Se trata de dos textos sobre las crisis cubanas de 1920-1921 y 1930-1933 ${ }^{15}$, y un tercero sobre la repatriación de españoles desde Buenos Aires y Montevideo durante la década de $1930^{16}$. Finalmente, en su obra sobre la política exterior de la Segunda República en América Latina, Tabanera describe algunas de las medidas tomadas por los gobiernos republicanos ante la avalancha de solicitantes de repatriación desde destinos americanos ${ }^{17}$.

Por otro lado, de la puesta en práctica de los postulados del mencionado artículo 46 en su primera década de vigencia existe información cuantitativa

12 NÚÑEZ SEIXAS, 115, 31/1 (Varsovia, 2005): 117-142; 2000, 3-38. Los trabajos de C. Frid abordan el retorno desde la lógica de los lugares de destino y los de F. Erice desde el lugar de origen. FRID, 11-12 (Santiago, 2001): 53-72. ERICE, 2000: 39-73.

13 MARSAL, 1969: 379-406. El libro es un largo relato biográfico de un inmigrante repatriado por el Estado español después de varias décadas de difícil experiencia migratoria en Argentina. La obra es pionera desde el punto de vista metodológico - la historia de vida - y por los temas que trata - las dificultades que entraña la emigración-, así como por su intento cuantificador a partir de una pequeña muestra.

14 Incluso en las diversas obras colectivas sobre la emigración española a América la cuestión apenas se menciona. DURÁN, 1992: 409-425. ARÓSTEGUI, 1992: 435-459. CUESTA, 2006: 380-407.

15 NARANJO Y MORENO, 536-537 (Madrid, 1990): 203-230. HERNÁNDEZ GARCÍA y HERNÁNDEZ GONZÁLEZ, 39 (Madrid, 1993): 583-607.

16 HERNÁNDEZ GARCÍA, 1990: 93-115.

17 TABANERA, 1993: 101-109; 7 (París, 1999): 73-93. 
para el caso de la comunidad española establecida en México ${ }^{18}$. Durante la revolución mexicana (1910-1920), algo más de mil doscientos individuos lograron retornar a España con un pasaje subvencionado, lo que supone una estimación en torno al siete por ciento del total de españoles que salieron del país en los años en que el saldo migratorio se tornó negativo (1914-1917) ${ }^{19}$. La guerra revolucionaria tuvo consecuencias graves para la economía mexicana y también para los modos de vida de los españoles, sobre todo en la capital, donde se concentraba el grueso de inmigrantes establecidos en ese país y también el mayor número de asalariados. Aquellos que se marcharon con un billete gestionado por el consulado español o la Sociedad de Beneficencia Española de México, la principal institución asistencial de la colonia, lo hicieron en su mayoría en calidad de «desempleados»o «indigentes» y todos ellos $\sin$ recursos para viajar por su cuenta ${ }^{20}$.

Durante la crisis económica posterior a la Primera Guerra Mundial (19191921), algunos países americanos sufrieron de manera notable las consecuencias de la contracción del comercio internacional y la disminución de las importaciones estadounidenses. Cuba decretó una moratoria de pagos en enero de 1921 que afectó al sistema bancario de la isla, hizo caer de manera exorbitante los precios del azúcar y provocó el desempleo de miles de inmigrantes españoles que acudían de forma estacional a la zafra ${ }^{21}$. En los meses siguientes a la quiebra, los jornaleros acudieron en masa en varias ocasiones ante las puertas del consulado, solicitando la protección de las autoridades españolas y la repatriación asistida. Las compañías navieras elevaron los precios de los pasajes, mientras los inmigrantes veían desaparecer sus ahorros y la posibilidad de adquirir el billete por sus propios medios. Según Naranjo y Moreno, en los meses estivales de 1921 y 1922, sin actividad en las zafras, el Consulado español en La Habana repatrió a 250 individuos al mes, cantidad que se reduciría poco después ${ }^{22}$.

Casi una década más tarde, la recesión internacional de 1929 provocó una contracción de los mercados mucho más fuerte que la anterior, el hundimien-

18 GIL LÁZARO, 2008; LX/2, 238 (México, 2010): 1001-1057. Ello a pesar de que México no fue un país de inmigración masiva española. En 1910 la población española en el censo nacional mexicano era de unos treinta mil individuos.

19 GIL LÁZARO, LX/2, 238 (México, 2010): 1028-1039. Una fuerte crisis derivada del conflicto armado afectó a la capital de tal manera que la historiografía posterior ha denominado al período entre 1914 y 1917 como «los años del hambre».

20 GIL LÁZARO, LX/2, 238 (México, 2010): 1039-1053.

21 NARANJO Y MORENO, 536-537 (Madrid, 1990): 203-208. Más recientemente, Julio A. Yanes ha explorado la repatriación de inmigrantes canarios desde Cuba durante la crisis de la posguerra mundial y la Gran Depresión a través de la prensa local canaria. YANES MESA, 25 (Murcia, 2009): 373-387.

22 NARANJO Y MORENO, 536-537 (Madrid, 1990): 220. 
to de los precios mundiales de muchos productos básicos y el desempleo masivo en países americanos con economías agro-exportadoras. Según Maluquer, «los españoles alcanzaron en estos años, junto a los británicos, las más elevadas tasas de retorno del mundo ${ }^{23}$. De nuevo, un alto número de individuos de origen español, residente en naciones como Argentina, Uruguay, $\mathrm{Cu}-$ ba o México, solicitó un pasaje subvencionado a causa de la pérdida del empleo y los medios de subsistencia. Tabanera cita algunos datos hallados en los informes del Consulado General de España en Cuba: en 1932 fue repatriado un diez por ciento del total de españoles que abandonó la isla ese año, en torno a las tres mil personas, cifra que se elevó a un 16,2 por ciento tan solo un año después ${ }^{24}$. Hernández García menciona porcentajes similares para las ciudades de Buenos Aires y Montevideo en el año 193125. Respecto a México, la cifra de españoles que abandonaron el país con un pasaje semi-gratuito o gratuito entre 1929 y 1936 se elevó a 1354 individuos $^{26}$. Si en 1931 los repatriados representaban una estimación de un seis y medio por ciento del total de personas retornadas, el porcentaje ascendió a más de la mitad de los que se marcharon en los peores años de la crisis (el bienio 1932-1933), en su gran mayoría desde la capital mexicana.

A pesar de los datos presentados, la información existente acerca del número de repatriados no deja de ser escasa, fragmentaria y dispersa, lo que impide conocer por el momento el alcance cuantitativo de este retorno tutelado o subvencionado. Los ejemplos que se han citado de repatriaciones efectuadas desde Argentina, México y Cuba no permiten suponer que la protección fuera significativa desde el punto de vista numérico, aunque, como se verá a continuación, el proceso de la repatriación involucró de manera efectiva los esfuerzos de legisladores, funcionarios, asociaciones e individuos a ambos lados del océano.

\section{TRES FASES DE LA REPATRIACIÓN DESDE 1907 HASTA 1936}

La aplicación del artículo 46 constituyó una constante fuente de problemas para los organismos estatales encargados de las cuestiones migratorias a lo largo del período ${ }^{27}$, así como para las autoridades consulares en los países

23 MALUQUER DE MOTES, XXV/II (Madrid, 2007): 146

24 TABANERA, 7 (París, 1999): 91.

25 HERNÁNDEZ GARCÍA, 1990:104, 113.

26 GIL LÁZARO, 70 (Valencia, 2011): 11-15.

27 ESPUNY et. al., 2011: 130-137. A partir de 1907 dos instancias dependientes del Ministerio de la Gobernación, el Consejo Superior de Emigración y el Negociado de Emigración, se ocuparon de la acción tutelar del Estado sobre los emigrantes. A ellas se añadió, un 
receptores y los encargados de las asociaciones asistenciales españolas en ultramar, debido, sobre todo, a la vaguedad con que fueron redactadas sus principales medidas. Esto daba pie a diferentes interpretaciones del mismo, a cálculos erróneos del veinte por ciento de los emigrantes salidos en el trimestre anterior y a un funcionamiento a menudo improvisado y errático por parte de las diversas oficinas encargadas, condicionado, casi siempre, por el espinoso asunto de la financiación de los pasajes y los gastos aledaños.

\section{Primera fase: de 1907 a 1924}

Los años transcurridos desde la aprobación y reglamentación de la ley migratoria, entre 1907 y 1908, hasta la primera reforma de la misma en 1924, constituyeron una muestra palpable de los límites de una legislación casuística y muy subordinada desde sus orígenes a las presiones de las diversas coyunturas socioeconómicas ${ }^{28}$. Ese tiempo, que coincide con el momento de mayor flujo migratorio español hacia América (gráfico 1), configuró una primera fase donde se puso a prueba el artículo 46 referente a la repatriación.

Aun cuando los aspectos relativos a la repatriación contenidos en la ley de 1907 no fueron motivo de modificaciones substanciales durante estos primeros diecisiete años, la interpretación y el cumplimiento efectivo de los mismos dieron lugar a la emisión reiterada de órdenes circulares desde el Ministerio de Estado español y los organismos encargados de las cuestiones migratorias. La vacilante ley y su corolario repatriador originaron, además, fuertes críticas desde diversas instancias contra la aplicación deficiente del apartado repatriador y la total ineficacia en su misión protectora ${ }^{29}$. Según Sánchez Alonso, dichas insuficiencias serían revisadas en las Cortes españolas en 1916, pero la repetida apelación a una necesidad de reformas en profundidad a la ley no llegaría a producirse sino hasta tiempo después, cuando se generalizaron las limitaciones a la inmigración, justificadas por el impacto

año después, una red de Inspectores de Emigración destacados en las poblaciones expulsoras. En 1924 el Consejo y el Negociado fueron liquidados y en su lugar se creó la Dirección General de Emigración, dependiente del Ministerio de Trabajo. En 1929, la Dirección fue sustituida por la Inspección General de Emigración, también bajo dependencia del Ministerio de Trabajo. Finalmente, en 1931, ante la avalancha creciente de solicitudes de repatriación, el gobierno republicano trasladó la Inspección al Ministerio de Estado, pero tan solo cuatro años después y ante su inoperatividad, aquella volvió a depender del Ministerio de Trabajo.

28 PÉREZ-PRENDES, 1992: 86-104. Pérez-Prendes recalca que, en su formulación, la ley mostraba una gran incomprensión del verdadero carácter del fenómeno migratorio.

29 BADÍA MALAGRIDA, 1920: 83. En su Ideario de la colonia, el cónsul español en Veracruz, Carlos Badía, llamaba la atención sobre la insuficiente dotación de recursos de los consulados para efectuar las repatriaciones. 
de la crisis pos-bélica, y siguiendo el modelo restrictivo estadounidense de principios de $1920^{30}$.

Respecto a los procedimientos seguidos, el Consejo Superior de Emigración enviaba instrucciones a los consulados españoles en América y a las compañías navieras, y, al mismo tiempo, establecía comunicación con organismos privados asistenciales de las comunidades españolas residentes en los países de inmigración ${ }^{31}$. Buena parte de las órdenes expedidas en esta época trataban de corregir los problemas derivados del incorrecto cumplimiento del reglamento migratorio. Así, por ejemplo, una Real Orden de 1914 informaba a los funcionarios consulares acerca de la conducta que debían seguir en el caso de que las compañías navieras se negaran a cumplir el deber impuesto por el artículo 46 de la ley - algo bastante usual si nos atenemos a las quejas constantes de los cónsules y la reiteración de disposiciones similares desde Madrid $^{32}$ - Estas debían ordenar el embarque de los inmigrantes en el primer vapor que regresara a la Península y que perteneciera a «cualquiera de las compañías autorizadas», informando de ello al Consejo de Emigración. La compañía que motivara una repatriación en esas condiciones quedaría obligada a abonar, a la que finalmente la llevó a cabo, el importe completo del pasaje «sin perjuicio de la sanción penal correspondiente». En último caso, si alguna compañía se negaba a cumplir lo estipulado, el Consejo ordenaba que fueran satisfechas las cantidades de dichos pasajes utilizando para ello la fianza del naviero responsable ${ }^{33}$.

Otro de los escollos característicos del artículo 46 consistió en que no se sobrepasasen los límites marcados en 1907. En 1915 una circular dirigida a los consulados exigía la estricta observación de lo establecido por la ley, en concreto lo referido al medio pasaje gratuito y el veinte por ciento de emigrantes, ya que era palpable para el Consejo de Emigración que «los buques de la Trasatlántica Española han llevado con exceso dicho 20\% correspondiente a los trimestres del año anterior $[\ldots]\rangle\rangle^{34}$. Así, por ejemplo, a fines de ese año, el marqués de Lerma, ministro plenipotenciario de España en México, obligó al cónsul en Veracruz a restringir las repatriaciones a costa del Estado español, debido «la escasez de créditos concedidos para este servicio y ser imposible arbitrar nuevos recursos». El ministro daba la orden de que solo se

30 SÁNCHEZ ALONSO, 1995: 85-92.

31 AGAE, CEM, cajas 9647-9699, Apartados de Correspondencia General y Repatriaciones, 1906-1922.

32 GIL LÁZARO, 2008: 248-254.

33 Real Orden circular núm. 537, AGAE, CEM, caja 9655, 1.VII.1914.

34 El Consulado de España en México al Ministerio de Estado, AGAE, CEM, caja 9665, s/f, [1916]. 
concedieran las más precisas y «nunca como hasta ahora» ${ }^{35}$. Durante la crisis cubana de 1921-1922, la suspensión de créditos con los cuales pagar los pasajes a los españoles sin trabajo retenidos en la isla provocó que las asociaciones de inmigrantes en La Habana escribieran al Ministerio de Estado en demanda de nuevas partidas ${ }^{36}$.

La financiación de las repatriaciones constituyó, sin duda, el aspecto más controvertido, lo que obligó a una constante revisión de los contenidos de la ley. A fines de 1922, una Real Orden enviada desde el Ministerio de Estado informaba a las legaciones y consulados en América de que las elevadas cuentas que presentaba la Compañía Trasatlántica Española por el importe del quebranto ${ }^{37}$ comprometían los recursos del presupuesto ministerial. Y es que las agencias consulares, sin contar con la autorización oficial, disponían a menudo de las cantidades y desequilibraban los cálculos —al parecer nunca precisos, según la Orden - de los créditos destinados a la repatriación ${ }^{38}$. Estas dificultades se repetirían también a lo largo de la década de 1920, generando una emisión constante de reales órdenes con ajustes de la ley y recordatorios a las autoridades destacadas en los países americanos. El resultado fue que los organismos encargados de la financiación de la acción estatal sobre la emigración - la llamada Caja de Emigración, primero, y el Tesoro del Emigrante, después - destinaron cada vez partidas mayores de sus recursos a la asistencia a los repatriados ${ }^{39}$.

35 El ministro plenipotenciario de España al cónsul de España en Veracruz, AGAE, EEM, caja 327, 18.XI.1915. En el caso concreto de la repatriación desde México, la coyuntura revolucionaria incitó a las autoridades a sobrepasar el estricto cálculo del veinte por ciento una y otra vez.

36 Sociedad de Beneficencia de Naturales de Cataluña, Sociedad Montañesa de Beneficencia, Sociedad de Beneficencia Gallega, Sociedad de Beneficencia Asturiana y Centro Balear, AGAE, AE, caja 1697, 26.VI.1922.

$37 \mathrm{La}$ diferencia entre la cantidad que abonaban los consulados por el transporte de repatriados y el costo del pasaje que tenían derecho a cobrar las compañías navieras.

38 Ministerio de Estado a la Legación de España en México, AGAE, CEM, caja 9700, 15.XII.1922. Por ello, en adelante las autoridades centrales ordenaban que «no realice ningún Consulado embarque alguno que devengue gastos sin contar con la previa y expresa autorización de este Departamento».

39 ESPUNY et. al., 2011: 130-137. La Caja de Emigración, en funcionamiento a partir de 1908, cubría los gastos de la tutela de los emigrantes. Sus fondos se nutrían de diversas partidas: una asignación anual variable fijada en los presupuestos del Estado, el importe de los permisos de los navieros para transportar emigrantes, el dinero recogido en concepto de multas por infracción de las disposiciones sobre emigración, los ingresos que producían las publicaciones del Consejo, los donativos y subvenciones procedentes de corporaciones y particulares y algunos otros apartados menores. 


\section{Segunda fase: el código de 1924 y la aplicación del artículo 47 en la déca- da de 1920}

Las disposiciones legales migratorias posteriores a 1907 fueron refundidas en un nuevo código en 1924, en el contexto de la dictadura de Primo de Rivera y la revitalización del flujo migratorio posterior a la crisis de la primera posguerra (gráfico 1). Desde ese año, pues, se extiende una segunda etapa en la repatriación que duró hasta 1931. En la remodelación de 1924 el artículo relativo a la repatriación pasó a ser el 47.

La administración española durante la dictadura primorriverista alentó y amplió cada vez más la esfera de influencia de los organismos privados de asistencia y socorro de los inmigrantes en los países de recepción, confiando en buena medida la gestión y financiación de las repatriaciones a las asociaciones de socorros mutuos, las sociedades de beneficencia y otras instituciones de carácter fundamentalmente asistencial, en colaboración estrecha con los consulados, aunque no exenta de tensiones y contradicciones.

A partir de esta refundición de la ley en 1924, la protección estatal ya no se ceñiría a la travesía del emigrante, sino que debía extenderse también a su estancia en el extranjero y a su viaje de retorno, exigiéndose, además, garantías certificadas a ciertos tipos de emigrantes que la ley consideraba objeto de protección frente a los posibles especuladores ${ }^{40}$. Dicha protección del emigrante en su destino seguiría en manos de los cónsules españoles, con la ayuda de unas Juntas Consulares, de nueva creación, mientras que la función protectora se vio reforzada, al menos en el papel, con la creación del Tesoro del Emigrante cuyos fondos se destinarían al socorro de emigrantes y repatriados y a la subvención de «asociaciones y centros patrióticos españoles», asistenciales o de enseñanza, en el exterior. Se esperaba que la existencia de fondos para subvenciones activara la participación de instituciones privadas en las que el Estado pudiera delegar algunas de las funciones tutelares en los países receptores americanos, sobre todo en el apartado repatriador ${ }^{41}$.

El concepto de emigrante emanado de la reforma de 1924 también supuso una novedad respecto al reglamento anterior, ya que ahora la ley los reconocía como «los españoles o sus familias que, por causa de trabajo, abandonen

40 VÁZQUEZ GONZÁLEZ, 1992: 248.

41 TABANERA, 7 (París, 1999): 82. Instituido en 1924, el Tesoro del Emigrante se nutría con las patentes de los navieros, consignatarios y oficinas de información y de pasaje de emigrantes; con el importe de las multas impuestas por infracciones de la ley, de su reglamento y de las disposiciones complementarias; con el canon sobre billetes de inmigrantes y repatriados; con el producto de las publicaciones de la Dirección General y las subvenciones y donativos que concedían las corporaciones y particulares. No tuvo dotación presupuestal del Estado. 
el territorio nacional para establecerse fuera de él definitiva o temporalmente». Desde las tribunas oficiales se tenía la esperanza, además, en lo que aquí nos ocupa, de que una mayor claridad en la definición de emigrante permitiera a las compañías navieras y los consulados un cálculo más preciso del citado veinte por ciento de repatriados ${ }^{42}$. El artículo 47 incorporó por primera vez la gratuidad del pasaje para aquellos individuos que fueran rechazados por el país de acogida debido a la aplicación de nuevas disposiciones en caso de que fueran conocidas en España por la compañía naviera en el momento de la salida ${ }^{43}$.

La documentación de los repatriados — la falta de ella en muchos casosconstituyó uno de los principales problemas legales que afrontaron las autoridades consulares durante este período. El alto número de inmigrantes que, o bien nunca se habían registrado en un consulado, o no tenían actualizado su registro de matrícula en el momento de solicitar su repatriación, hacía mucho más complejo y lento el proceso ${ }^{44}$. Así, una Real Orden de diciembre de 1924 recordaba lo dispuesto para la aplicación de la Ley de Registro Civil en el extranjero: se exigía a quienes solicitasen la expedición de certificados de nacionalidad los documentos necesarios para justificar su calidad de súbditos españoles, como su pasaporte o cédula de identidad, documentos militares o de inscripción marítima, o, en caso de que su autenticidad ofreciera dudas, una información jurada, firmada por testigos de reconocida solvencia moral e inscritos con anterioridad en la agencia de turno ${ }^{45}$. En 1925 se emitió una nueva Orden que estipulaba que, en casos excepcionales en que se solicitara con urgencia la «repatriación de alienados españoles», se permitiera considerar como prueba plena de la nacionalidad de los interesados los certificados de nacionalidad expedidos por los cónsules de España en el extranjero ${ }^{46}$.

A fines de los años veinte la crisis económica comenzó a erosionar las frágiles costuras sobre las que se levantaba el entramado legal y financiero de las repatriaciones. Un Real Decreto de 24 de enero de 1930 permitió por primera vez a los emigrantes salir de España con contrato de trabajo, prohibido hasta

42 Inspección General de Emigración, 1933: 561.

43 Ley de Emigración de 1924, Capítulo IV, Artículo 47. Inspección General de Emigración, 1932: 612 .

44 Diversos autores sitúan en esta década el mayor número de salidas clandestinas de jóvenes que huían del servicio militar en el contexto de guerra colonial española en Marruecos. Véase SÁNCHEZ ALONSO, 1995:36.

45 Ministerio de Estado, Real Orden de 3 de diciembre de 1924, AGAE, EEM, caja 477, 3.XII.1924. La utilización de esta vía, que encontraba cauces naturales en las redes primarias de los inmigrantes, sería de gran utilidad para los solicitantes de repatriación «indocumentados». Véase GIL LÁZARO, 2008: 269.

46 El Ministerio de Estado al ministro plenipotenciario en México, AGAE, EEM, caja 477, 14.V.1925. 
entonces. Meses después, en septiembre de 1930, una Real Orden del Ministerio de Trabajo y Previsión español no solo lo permitía, sino que condicionaba la emigración a la presentación de un contrato de trabajo en el país de destino junto a un depósito por el importe del pasaje de regreso. Esta medida se justificaba por el elevado coste de la repatriación de emigrantes en el exterior, que el Estado se estaba viendo obligado a efectuar de forma masiva ${ }^{47}$.

A lo largo del año 1930, la Inspección General de Emigración canceló varias veces la concesión del veinte por ciento de pasajes gratuitos de repatriación que estipulaba la ley ${ }^{48}$. Entre las razones que se dieron se hallaba el hecho notorio de que la emigración española a las repúblicas americanas había descendido mucho, y todo parecía indicar que esa tendencia continuaría. Según la Inspección, las causas de esta disminución radicaban en las dificultades económicas que en esos momentos afligían a los países de ultramar ${ }^{49}$. La reducción de las salidas afectaba directamente al porcentaje de repatriados en cada vapor y, en el contexto de crisis, las compañías se mostraron más renuentes que nunca a transportar inmigrantes bajo la subvención prevista por la ley migratoria.

La Inspección General, por otra parte, no contaba con una dotación en los presupuestos del Estado, sino que se sostenía mediante el pago por las compañías navieras de gravámenes proporcionales al tonelaje de los buques utilizados en el tráfico migratorio y al número de billetes expedidos ${ }^{50}$. La disminución del tráfico redujo la principal fuente de ingresos de dicho centro, cuyos fondos en los años anteriores habían sufrido un considerable descenso, «por haber costeado un excesivo número de repatriaciones gratuitas y haber asumido otros gastos inherentes a ellas» $\rangle^{51}$. La crisis que finalizó con la renuncia a fines de enero de 1930 de Miguel Primo de Rivera, y el vacío político que le siguió contribuyó a la falta de atención dada por las autoridades españolas al problema de las repatriaciones ${ }^{52}$. En este sentido, un informe del encargado de despacho de la embajada española en Buenos Aires de diciembre de 1930 transmitía una queja interpuesta por la Federación Regional de Sociedades Españolas (que reunía a 25 asociaciones con un total de 6.440 miembros) ante la preocupante situación de gran número de emigrantes necesitados de una repatriación inmediata. También se aludía en dicho informe a

47 Inspección General de Emigración. «Cancelación de pasajes gratuitos a españoles indigentes residentes en América», AGAE, CEM, caja 9761, 1930.

48 Compañia Trasatlántica Española al cónsul de la República Española en México, AGAE, CEM, caja 9822, 26.I.1932.

49 Inspección General de Emigración, 1933: 590.

50 Consulado General de España en México, AGAE, CEM, caja 9761, 23.II.1931.

51 Consulado General de España, AGAE, CEM, caja 9761, 23.II.1931; Supresión de pasajes, caja 9870, 23.II.1933.

52 SÁNCHEZ RIVAS, 1930: 34. 
la carencia de fondos en las oficinas consulares y a la inactividad de la representación oficial ${ }^{53}$.

\section{Tercera fase: las medidas republicanas}

Si bien la configuración legal migratoria de 1924 duró hasta 1960, los años que transcurren entre 1931 y 1936 encierran una tercera fase en este período, determinada por la obligada adaptación de los gobiernos republicanos a las circunstancias extraordinarias impuestas por la crisis económica internacional y su reflejo en los flujos migratorios trasatlánticos, que, por tercera vez desde 1907, arrojaron un saldo negativo (gráfico 1).

Como ya se ha reiterado, el impacto de la crisis económica a principios de 1930 en los países americanos, así como la repercusión de la misma en las comunidades españolas de inmigrantes allí establecidas, se tradujeron en la reducción abrupta de las salidas (como en toda Europa) y en el inicio de una corriente de retorno masiva de emigrantes. Cuando no fueron los efectos directos de la crisis en el empleo, fueron las medidas restrictivas de los gobiernos para combatirla las que afectaron a los negocios españoles y sobre todo a los inmigrantes asalariados ${ }^{54}$.

Los legisladores republicanos, en consonancia con este nuevo y apremiante problema, se concentró, no ya en organizar la emigración, sino en repatriar a connacionales con dificultades en los países de acogida. Según N. Tabanera, es comprensible que no se emitiera una nueva ley migratoria en estos años y que la actuación legislativa se orientara a paliar los efectos de la crisis sobre quienes habían emigrado con anterioridad, así como a obstaculizar las salidas hacia donde pudieran tener pocas garantías de éxito. Las dificultades con las que se podrían encontrar los recién llegados en el mercado de trabajo ameri-

53 El encargado de despacho de la Embajada española en Buenos Aires al Ministerio de Estado, AMAE, R. leg. 505, exp. 10. 30.12.1930.

54 MALUQUER DE MOTES, XXV/II (Madrid, 2007): 147. Las medidas más perjudiciales para la población extranjera residente en los países de inmigración fueron las leyes de trabajo que limitaban la presencia de trabajadores foráneos en los mercados de trabajo nacionales. Ya se habían impuesto con anterioridad medidas de este tipo para defenderse de los efectos de la crisis de la primera posguerra mundial en países como Chile, El Salvador, Uruguay y Guatemala. En México el ejecutivo aprobó una nueva legislación laboral, la Ley Federal de Trabajo, en agosto de 1931, por la cual se limitaba a un diez por ciento el número de extranjeros en negocios del tipo que fuera con una plantilla superior a los cinco empleados. Similar medida fue aprobada en Cuba a través de los decretos de nacionalización del trabajo de 1933. También Perú, Venezuela y República Dominicana aprobaron leyes similares con una incidencia algo menor en las colonias españolas allí establecidas. 
cano inclinaron a las autoridades a negar la concesión del pasaporte a quien no presentara antes de la salida un contrato laboral en regla ${ }^{55}$.

Las repatriaciones en los primeros meses del nuevo Estado republicano se efectuaron a través de la legislación previa. Ya desde el inicio de 1931 se empezó a exigir un depósito antes de que el emigrante saliera del país para asegurar el pago de posibles gastos de repatriación, sobre todo si la elección del destino recaía en países con «dificultades económicas conocidas» ${ }^{56}$. En 1932 se limitó el derecho a la expatriación exigiendo «en favor de determinadas clases de emigrantes un mínimum de garantías». La intención de esta limitación de la ley no era otra, según el comunicado de la Inspección de Emigración, que la de «evitar que los vencidos en la lucha y repatriados a título de indigentes por cuenta del Estado» sufrieran los rigores de un nuevo fracaso, disponiendo que no pudieran volver a emigrar en el plazo de tres años si no reintegraban previamente los gastos que su repatriación hubiera ocasionado. Una nueva modificación en 1933 retiraba el plazo citado, lo que obedeció al razonamiento de que no era una cuestión de plazo lo que daría la garantía de que el emigrante «que ya cayó una vez en la indigencia no vea repetido su infortunio». A él más que a otro, había que suponer como «inadaptable» en el país de inmigración y el espíritu de previsión tutelar de la ley obligaba a advertirle de ese peligro. Por ello, la advertencia no podía concluir «pasado un término en el que no había cesado la causa» ${ }^{57}$.

El exiguo número de salidas verificadas durante la crisis, las diferencias habidas entre las compañías navieras y los cónsules en cuanto al cumplimiento del servicio de repatriación, así como el aumento espectacular del número de inmigrantes que solicitaron su repatriación desde distintos puntos de la geografía americana, llevó a la Inspección General de Emigración a idear un nuevo procedimiento de liquidación a las compañías, puesto en marcha desde el inicio del año 1933. Este nuevo sistema de repatriación gratuita fue, sin duda, el cambio más significativo de los registrados a lo largo de este período en cuanto a la reglamentación del proceso de repatriación ${ }^{58}$. El decreto que regulaba el nuevo sistema establecía que el cálculo de lo que se llamó «repatriación bonificada» se efectuaría en cada embarque por el Inspector del puerto, en el momento de formalizar las listas de pasajeros y ateniéndose al número de emigrantes que figuraran en ellas. Una vez realizado el embarque, el

55 TABANERA, 7 (París, 1999): 87.

56 Ministerio de Estado, Reales órdenes circulares dirigidas a Embajadas, legaciones y Consulados españoles, AMAE, Madrid, Ministerio de Estado, 11.II.1931. Véase también Inspección General de Emigración, 1933: 925.

57 AGAE, CEM, caja 9870, Ministerio de Estado, 30.IX.1933.

58 Ministerio de Estado, Inspección General de Emigración, AGAE, CEM, caja 9870, 19.IX.1933. 
consignatario del buque entregaría al Inspector tantos vales (o «bonos») para billetes gratuitos como correspondiera al veinte por ciento de los emigrantes embarcados $^{59}$. Dichos talones serían válidos para repatriaciones a mitad de precio, si bien en casos de estricta necesidad, podrían utilizarse dos de ellos para completar un solo pasaje gratuito.

Así pues, era tarea de los inspectores contabilizar el total de plazas embarcadas al final de todas las listas de emigrantes, así como el cálculo del veinte por ciento que correspondía repatriar. Había cinco tipos de vales: A, B, C, D y E. El talón A debía ser entregado al consignatario del buque, una vez cumplimentado por el Inspector del puerto. El consignatario anotaría en un libro el nombre de la nave, la fecha de salida, el número de emigrantes, el cálculo del porcentaje de individuos a repatriar y el total de bonos recibidos del inspector. La Inspección abriría también un libro de registro de entradas de bonos por inspectores (talón B) y compañías de navegación (talón C) y, al mismo tiempo, una cuenta por cada consulado (talón D) con el número de orden de cada bono y la compañía expedidora, el buque y la fecha de expedición. En caso de necesidad, se pudo disponer de los talones sobrantes en un consulado para atender las necesidades de otro ${ }^{60}$.

Las reglas establecidas respecto a las fichas correspondientes a cada repatriado (talón E) eran muy meticulosas para evitar confusiones e imprecisiones. Así, acerca del oficio del repatriado, no debía utilizarse el término «jornalero» más que en los casos en que el interesado careciera de aptitud o profesión determinada ${ }^{61}$. Habría de hacerse una ficha para cada persona repatriada, separando la de los hijos y la del cabeza de familia, a menos que el pasaje de aquellos fuera enteramente gratuito por razón de la edad. Para la liquidación de cuentas de las compañías esa ficha constituía el documento probatorio esencial de que la empresa naviera había cumplido con la obligación impuesta por el artículo 47 de la Ley de Emigración. Por otro lado, la Inspección construiría con ellas unas estadísticas de repatriación, cuya misión era orientar acerca de la situación en la nación de procedencia de la ficha. Entre las causas que aconsejaban la repatriación no se debía consignar ni la de

59 Ministerio de Estado en Madrid, Inspección General de Emigración, AGAE, CEM, caja 9870, 19.IX.1933. Dichos inspectores enviarían a la Inspección General, unidos a las listas de cada embarque, los vales correspondientes al mismo, y la Inspección los remitiría a los cónsules de la nación en los países «donde deban ser utilizados con las instrucciones pertinentes para su adecuado empleo».

60 Ministerio de Estado, Inspección General de Emigración, AGAE, CEM, caja 9870, 23.IX.1933. Por esa razón, cada oficina consular debía comunicar a la Inspección el número aproximado de repatriaciones (tanto a mitad de precio como gratuitas) que calcularan iban a realizar en el trimestre siguiente.

61 Ministerio de Estado, Inspección General de Emigración, AGAE, CEM, caja 9870, 24.III.1934. 
«indigencia» ni la de «falta de recursos», ya que estas se suponían «inherentes a la calidad de repatriados», según el documento de la Inspección. En cambio, las fichas debían expresar aquellas causas que obligaban a la concesión del pasaje, tales como falta de trabajo, enfermedad, motivos políticos (posibilidad de deportación o expulsión), leyes de trabajo adversas a los extranjeros, obligación del servicio militar, orfandad, naufragio, etc. ${ }^{62}$. Asimismo, debía consignarse el tiempo de expatriación $\mathrm{y}$, con el mayor cuidado, la formación del emigrante, para que no sucediera que individuos que figuraban en la ficha «con instrucción» aparecieran en la misma no sabiendo firmar. En este sentido se precisaba que «este detalle es de gran interés por cuanto la falta de instrucción del emigrado puede ser factor importante en su fracaso» ${ }^{63}$.

La repatriación bonificada, a pesar del rigor y control burocrático que introdujo, era un sistema complejo desde su inicio, por cuanto contabilizar el número de emigrantes suponía distinguir a los pasajeros en categorías que los pasajes de barco no daban de forma inmediata. Esto favoreció una vez más que las empresas de transporte trataran de evadir su obligación siempre que pudieran y que esa mayor burocratización no acabara con los problemas que arrastraba el artículo repatriador desde su formulación.

Pese al nuevo sistema, el problema persistente de las repatriaciones en este último período siguió siendo la financiación de los pasajes. Según N. Tabanera, la falta de medios para la repatriación de indigentes constituyó una dificultad insuperable para los gobiernos, trascendió a los medios de comunicación nacionales y recibió una amplia atención en las sesiones de las Cortes. Las respuestas del ejecutivo a las interpelaciones parlamentarias concluían, por regla general, con la idea de que el Estado carecía de fondos para poder cubrir las necesidades de repatriación ${ }^{64}$.

\section{LAS INSTITUCIONES EN LA REPATRIACIÓN DE INMIGRANTES}

En marzo de 1931 el cónsul español en Buenos Aires explicaba su situación en los siguientes términos:

Todas las mañanas el Consulado General, durante un par de horas está convertido en bolsa de trabajo, casa de beneficencia y consejo, y el Cónsul adjunto y yo atendemos... a dos largas listas de compatriotas que piden trabajo o socorro ya que

${ }^{62}$ Ministerio de Estado, Inspección General de Emigración, AGAE, CEM, caja 9870, 7.VIII.1934.

63 Ministerio de Estado, Inspección General de Emigración, AGAE, CEM, caja 9870, 30.X.1934.

64 TABANERA, 7 (París, 1999): 89. 
la repatriación es imposible. Y la Secretaría, entre tanto, funciona dando cartas de recomendación para empleos, para las sociedades regionales a fin de que ayuden a sus coterráneos; bonos para comer y para dormir, etc., y por la tarde los ordenanzas van a las estaciones de ferrocarril a sacar los boletos para aquellos de nuestros compatriotas para quienes se ha obtenido alguna ocupación agrícola en localidades poco distantes de la capital $[\ldots]^{65}$.

Los consulados españoles en América Latina ejercieron un importante papel en la repatriación de inmigrantes españoles entre 1907 y 1936. La acción de los cónsules se definió de forma clara por su carácter de mediadores entre las distintas instancias que formaban parte de este proceso, como muestra el pasaje previo. Su eficacia para dar respuesta a las demandas de ayuda se hallaba estrechamente unida a la capacidad de tender vínculos fuertes con las comunidades españolas y sus representantes, como los directivos de las asociaciones, pertenecientes a los estratos económicos más altos de las mismas ${ }^{66}$.

Las oficinas consulares eran los principales centros receptores de peticiones de repatriación y los cónsules tenían la última palabra en la decisión de quién sería repatriado y en qué momento. También llegaban solicitudes a las legaciones diplomáticas y a las oficinas de las asociaciones asistenciales, quienes debían remitirlas a los consulados. En ocasiones, tanto los ministros plenipotenciarios o los presidentes de alguna asociación recomendaban a inmigrantes de forma personal. Las instituciones mutuales y benéficas participaban a veces en la selección de candidatos, en caso de que los cónsules decidieran delegar esta tarea en ellas. Así por ejemplo, la Sociedad de Beneficencia Española, principal organismo filantrópico de los españoles de México, participó durante un período en dicha selección ${ }^{67}$.

Por otro lado, las más grandes y poderosas agrupaciones asistenciales creadas por los inmigrantes desempeñaron un papel esencial en el proceso repatriador, gestionando algunas de ellas su propia cuota de pasajes con las compañías navieras, mediante descuentos entre un veinte y un treinta por ciento del precio de los mismos ${ }^{68}$. Además, colaboraban activamente con los consulados en otras labores, siendo una de las principales la de solventar los

65 El cónsul español en Buenos Aires, Informe al Ministerio de Estado, AMAE, leg. 112, exp. 9. 08.III.1931.

66 GIL LÁZARO, 70 (Valencia, 2011): 82.

67 Memoria anual de 1925, MSBE, p. 9. Reglamento General de la Sociedad de Beneficencia Española, artículo $3^{\circ}$, sobre las atribuciones de la Comisión Calificadora. Un equipo interno de vigilancia y control - la Comisión Calificadora - se encargaba de hacer una investigación de los antecedentes económicos, laborales y morales de los inmigrantes antes de recomendar al Consulado la repatriación de los individuos que más lo necesitaran.

68 Memoria anual de 1906, MSBE, p. 10. El acuerdo de la Beneficencia con la empresa del Marqués de Comillas limitaba la concesión a cinco pasajes enteros de tercera clase en cada vapor. Otros ejemplos de acuerdos: GONZÁLEZ MARTÍNEZ, 2008: 368. 
gastos de manutención y asilo de los agraciados con un pasaje semi-gratuito - una vez que les llegara la confirmación consular - si hubieran dejado ya su vivienda o carecieran de recursos para mantenerse; esto debía suceder tanto si los individuos residían en la ciudad portuaria como si debían realizar un primer viaje desde su lugar de residencia hasta el puerto de salida. Por regla general eran los hospitales y asilos mantenidos por dichos organismos los que asumían el alojamiento de inmigrantes en sus instalaciones en los días previos al viaje. Cuando los solicitantes no tenían recursos, los viajes intermedios entre los lugares de residencia y el puerto solían ser sufragados con donativos procedentes de otros miembros del grupo migratorio a los que el consulado o las asociaciones contactaban para tal fin, aunque las instituciones también empleaban a menudo ciertas cantidades de sus presupuestos para pagar billetes de tren ${ }^{69}$.

Otras agrupaciones no asistenciales de los inmigrantes también colaboraron en las tareas repatriadoras. Así, por ejemplo, en el contexto de crisis económica que afectó a Cuba en 1921, la Cámara de Comercio e Industria española en La Habana puso a disposición del consulado todos sus locales y su personal para agilizar los trámites de las repatriaciones. El Centro Gallego o el Centre Català, ambos en Buenos Aires, también atendieron solicitudes de repatriación en momentos de crisis ${ }^{70}$.

Hasta la década de 1930, las empresas navieras europeas que cruzaban el Atlántico no lograron romper el cuasi-monopolio que la Trasatlántica Española retuvo desde fines del XIX en el traslado de emigrantes entre la Península y el continente americano ${ }^{71}$. De este modo, las repatriaciones asistidas se gestionaron sobre todo con esta empresa española hasta que las relaciones entre los gobiernos de la Segunda República y la naviera del marqués de Comillas se deterioraron ${ }^{72}$. Los agentes de las navieras en los puertos de embarque americanos establecían contacto con los consulados con el fin de efectuar el cálculo del veinte por ciento de los pasajes llevados a la ida durante el período establecido por ley. La negociación entre consulados y compañías solía

69 El Centro Asturiano de La Habana, por ejemplo, en su hospital «La Covadonga», o la Asociación de Dependientes de Comercio, en el Hospital de la Purísima Concepción. NARANJO y MORENO, 536-537 (Madrid, 1990):212.

70 NARANJO Y MORENO, 536-537 (Madrid, 1990): 207. LLORDÉN MIÑAMBRES, 2008: 51-90.

71 La formación de una corporación de navieras europeas denominada «Conferencia de París» forzó la competencia entre empresas en el Atlántico a partir de 1931, de la que no pudo sustraerse la Trasatlántica Española. Reglamento para Agentes y Líneas que forman la Conferencia, AGAE, CEM, caja 9870, s/f, [1931].

72 Por Decreto del 5 de mayo y Ley del 23 de julio de 1932 se rescindió el contrato vigente desde 1861 entre la empresa y el Estado español sobre la concesión de los contratos de transporte de pasaje y correo. Véase HERNÁNDEZ SANDOICA, 2 (Madrid, 1989): 120. 
desarrollarse en buenos términos aunque no faltaron ocasiones en que la comunicación se tornó áspera, debido a la emisión excesiva de pasajes de repatriación, lo que las navieras no solían aceptar de buen grado. En los momentos de crisis, los funcionarios consulares solicitaban a las empresas rebajas en los precios de los pasajes. Así, en junio de 1921 los presidentes de las asociaciones de beneficencia más importantes en Cuba decidieron enviar sendas cartas al Ministro de Estado de España y al gerente de la naviera española, con el fin de que se efectuara una rebaja en el pasaje de tercera ${ }^{73}$. Finalmente, la interacción con los agentes navieros y los capitanes de los barcos se extendía a la hora de asegurarse la protección de los repatriados durante la travesía - sobre todo si eran menores o mujeres, solas o acompañadas de sus hijos-.

Otro de los temas cruciales que se decidía entre las instancias gestoras era la forma en que iba a ser cubierto el costo completo del pasaje. Este a menudo dependía de un arreglo conjunto entre las sociedades asistenciales y los consulados para financiar el cincuenta por ciento que no proporcionaba el Estado español a través de las navieras. Así, en la mayoría de los casos, aún cuando la legislación preveía subvencionar los pasajes, la repatriación terminaba siendo un proceso en buena medida gratuito. Las autoridades, salvo contadas excepciones, se cercioraban de que enviaban de regreso a España a individuos verdaderamente necesitados de ello. Los repatriados, por regla general, no estaban en disposición de pagar un céntimo de su pasaje ni de los gastos aledaños (viajes, manutención y alojamiento) y se atenían de forma inevitable a los recursos ajenos, las subvenciones oficiales, la caridad o la filantropía de su grupo migratorio ${ }^{74}$. Es más, los cónsules y las asociaciones buscaban la manera de patrocinar el viaje desde el puerto de llegada del vapor hasta el lugar de origen de los individuos.

El aumento del número de solicitudes a partir de la segunda mitad de la década de 1920 impuso a las oficinas consulares un mayor grado de burocratización del proceso. Así, por ejemplo, en 1926 empezó a operar en el Consulado de España en México un libro de registro de solicitudes de repatriación, en el que quedaban anotados los nombres y direcciones de los peticionarios;

73 AMAE, leg. 748, exp. 7, 21.06.1921.

74 Las motivaciones de los gestores a la hora de hacer la selección eran diversas. Por un lado, las autoridades españolas pretendieron evitar abusos por parte de individuos que vieron en la repatriación un modo más barato de volver a España. En la documentación aparecen varios casos de estafa denunciados por otros solicitantes o las asociaciones. Por otro lado, los consulados tenían que cumplir a veces con ciertos compromisos, cuando las altas instancias diplomáticas o las asociaciones recomendaban a alguien que no se ajustaba estrictamente al perfil del solicitante pero que estaba bien arropado socialmente. Por último, desde las cúpulas de las asociaciones operó a lo largo del período un interés esencial por cuidar la imagen de sus comunidades como núcleos prósperos y florecientes, donde sobresaliera su industriosidad y no se mostrara la indigencia. GIL LÁZARO, 2008: 272-273. 
de esta forma entraban a figurar en una lista de espera. Este libro de registro incluía a su vez una lista paralela de peticiones preferentes, es decir, pertenecientes a aquellos inmigrantes que, con carácter de urgencia, el cónsul remitía a la Comisión Calificadora de la Sociedad de Beneficencia, para que esta examinara a la mayor brevedad posible la pertinencia de la concesión del pa$\mathrm{saje}^{75}$. Una vez efectuada la investigación de antecedentes, que podía demorarse un par de días en estos casos, la sociedad benéfica remitía el resultado al cónsul, quien decidía qué personas serían las agraciadas con pasaje gratuito y cuáles debían esperar la llegada de un vapor posterior ${ }^{76}$.

A pesar de los esfuerzos por parte de las instancias gestoras, la tensión por la espera o por las listas interminables generaron varias situaciones de conflicto en las cuales las autoridades consulares españolas se vieron obligadas a solicitar la ayuda de los gobiernos locales. El Consulado General en La Habana tuvo que recurrir a las autoridades cubanas durante la crisis de 1921-1922, con el fin de que le permitieran la instalación de un grupo numeroso de españoles indigentes en el campamento de Triscornia ${ }^{77}$. Algo similar ocurrió en el Estado de Veracruz, en México, en los meses de verano de 1922, cuando un amplio contingente de españoles llegó al puerto convencido de que el consulado español en esa plaza pagaría sus billetes de repatriación. La afluencia masiva desbordó la posibilidad de actuación del consulado, que tuvo que solicitar la ayuda de las autoridades locales para auxiliar a sus connacionales ${ }^{78}$. En varias ocasiones a lo largo de este período las autoridades consulares se vieron incluso obligadas a contener los disturbios originados por los inmigrantes en espera de un pasaje de repatriación. A fines de 1931, el cónsul en Buenos Aires escribía al Ministerio de Estado lo siguiente:

Como preveía en telegramas cursados desde abril, se ha producido hoy grave desorden en este Consulado General, como consecuencia carencia medios repatriación y socorro que demanda desocupación y crisis económica del país. A pesar de gran vigilancia fuera y dentro oficinas Consulado ejercía policía, penetraron esta mañana los españoles exasperados, armados con cuchillos, atacando ordenanza y empleados produciendo pánico consiguiente entre centenar personas que se hallaban oficinas. Hirieron a dos empleados, a uno de relativa gravedad, e intentaron penetrar en mi despacho rompiendo puerta cristales, no consiguiéndolo por resultar

75 El cónsul de España en México a José Casal, AGAE, CEM, caja 9761, 21.XII.1928. No se ha podido fijar el año de inicio del libro de registro, lo que parece claro es que se sitúa en la segunda mitad de la década de 1920.

76 La Sociedad de Beneficencia Española al cónsul de España en México, AGAE, CEM, caja 9762, 2.X.1930. Las evidencias parecen indicar que la decisión final del cónsul era simplemente una ratificación de la decisión de la Comisión Calificadora.

77 AGAE, AE, caja 1649, 20.VI.1921. En dicha ocasión el consulado recibió la ayuda del Centro Gallego de La Habana.

78 GIL LÁZARO, 2008: 212-215. 
heridos con fragmentos de los mismos. Acudió gran número agentes policía, cerrándose oficina mientras practicasen las diligencias del caso. Hállanse al presente a mi despacho Encargado Negociado, Autoridades y periodistas ${ }^{79}$.

El desbordamiento de las estructuras diplomáticas y consulares españolas por la creciente necesidad de mejorar las condiciones de vida de los españoles en situación de indigencia y la falta de presupuestos para lograrlo obligó a la participación de las agrupaciones españolas instaladas en las distintas repúblicas en la solución del problema. Desde el principio de la década de 1930 surgieron varias iniciativas institucionales con el objetivo de aunar esfuerzos para conseguir atender con eficacia el creciente número de solicitudes de repatriación que se cursaban ${ }^{80}$. Cámaras de Comercio e Industria, organizaciones de carácter recreativo, agrupaciones de mujeres de la burguesía y otros organismos pertenecientes a las comunidades migratorias se unieron con el fin de crear cajas de repatriación, recolectar donativos privados, organizar eventos benéficos para la recaudación de dinero (subastas, rifas, kermeses, etc.) y otras propuestas con las que lograr recursos privados que no dependieran de la cada vez más escasa llegada de emigrantes. Así, por ejemplo, se organizó un «Comité de Amparo Español» en Buenos Aires, organismo encargado de recaudar fondos (de corta vida) y uno similar fue creado en México por las llamadas «Damas del ropero», mujeres que trabajaban de manera voluntaria para la Sociedad de Beneficencia Española ${ }^{81}$.

La llegada a fines de 1931 de los diplomáticos representantes del primer gobierno republicano impulsó en distintas latitudes la creación de Cajas para repatriaciones de súbditos españoles indigentes. Con esta medida se trataba de establecer un régimen de financiación de la repatriación más espontáneo y menos centralizado, por el cual no recayera la responsabilidad económica únicamente en los organismos oficiales y las instituciones, sino que se canalizara a través de las redes informales de ayuda y el esfuerzo de los mismos sujetos. Sin embargo, el problema planteado en los años treinta con las repatriaciones sobrepasó en poco tiempo la capacidad de las instituciones gestoras; también la filantropía migratoria resultó insuficiente para afrontar la coyuntura de crisis durante la Gran Depresión.

\section{LA RED SOCIAL COMO INSTITUCIÓN GESTORA Y FINANCIADORA}

79 AMAE, leg. R. 112, exp. 25, 04.XI.1931.

80 La Cámara Española de Comercio de México al cónsul de España, AGAE, CEM, caja 9762, 28.I.1928.

81 AMAE leg. R. 112, exp. 19 y 23. 
De las decenas de solicitudes que llegaban a manos de los cónsules cada mes, tan solo unas cuantas fueron seleccionadas y los solicitantes obtuvieron el preciado pasaje de retorno. Pero, hasta ese momento, los inmigrantes interesados en esta ayuda oficial habían tenido que dar una serie de pasos y cumplimentar ciertos requisitos, sin los cuales no se habría obtenido un resultado favorable. La búsqueda de apoyos para su candidatura era uno de los más importantes y en este sentido los mecanismos propios de la red social de los inmigrantes se ponían en funcionamiento para colaborar en la causa de uno de ellos que quería regresar y no tenía medios propios para hacerlo.

Cabe señalar que los solicitantes sabían de la existencia de este recurso. Acudir a un consulado y solicitar la repatriación asistida se había convertido en una posibilidad conocida y aprovechada, un medio más, dentro del conjunto de nociones de actuación sobre la migración que acumulaban los individuos, de su bagaje cultural migratorio. Muy a menudo no sabían con certeza a qué instancia dirigirse y lo hacían indistintamente a una u otras (legaciones, sociedades benéficas e incluso, había quien escribía al Ministerio de Estado en Madrid o al rey Alfonso XIII); sin embargo, estaban informados de otros casos de compatriotas que volvieron con un pasaje similar o fueron aconsejados por amigos, vecinos, familiares, asociaciones o los mismos cónsules que sabían de ese recurso, para que procedieran así en caso de necesidad ${ }^{82}$. La voz se corría, en el caso de la repatriación, como en su día se había extendido la información sobre la emigración, y este sería un elemento clave para la dinamización del proceso. Las redes de comunicación que unían a los inmigrantes desde el momento de la llegada al país de acogida constituyeron un espacio de transmisión de conocimientos indispensables también para el momento del regreso al lugar de origen.

Las solicitudes enviadas iniciaban un proceso de tramitación con unos tiempos y pautas determinados. Entre la fecha de recepción de la solicitud en un consulado y la confirmación de concesión del pasaje podían pasar meses, o incluso años, como así sucedió en el primer lustro de 1930. Los inmigrantes debían encontrar quien los avalara, buscar contactos y visitar diferentes instancias de apoyo para que su expediente fuera considerado. Esto también tomaba su tiempo y no siempre se tenía un recomendador dispuesto a apoyar. La insistencia de los inmigrantes - a menudo demostrada a través de cartas mensuales - denotaba una espera nerviosa junto a cientos de individuos más en condiciones similares ${ }^{83}$.

Cuando los solicitantes no poseían ninguno de los documentos oficiales requeridos (certificados de nacionalidad, recibos al día del pago del registro

82 GIL LÁZARO, 2008: 263-264.

83 El cónsul de España en México a Arturo Arriola, AGAE, CEM, caja 9822, 27.IV.1932; Arturo Arriola al cónsul de España en México, AGAE-CEM, caja 9822, 2.X.1932. 
consular, etc.), los consulados condicionaban el inicio del trámite al completo arreglo de su situación legal. Como lo más común era que los individuos pidieran su repatriación con escasos recursos y algunos sin sus papeles en regla, esto exigía ciertas concesiones como la condonación de las deudas de registro, mientras se demostrara de alguna manera la nacionalidad y, al mismo tiempo, su imposibilidad de abonar el adeudo por su mala situación económica.

Las solicitudes debían ir acompañadas de dos o más cartas de recomendación. Si no las tenían, los individuos debían hacerse con ellas en el transcurso del proceso. Estas cartas debían estar escritas por otros españoles conocidos en la comunidad que conocieran a los solicitantes y dieran su palabra de que eran personas honradas y trabajadoras. Las recomendaciones también podían provenir de las instituciones recreativas, culturales, deportivas, regionales y económicas de las comunidades migratorias. Aun cuando los solicitantes se hubieran hecho con un aval conveniente, o su situación fuera acuciante en extremo como para que las instituciones tomaran el caso a su cargo enseguida, y consiguieran en un plazo breve la parte gratuita de su pasaje, todavía había que reunir la otra mitad. De nuevo la solidaridad étnica o el patriotismo cumplían aquí un papel esencial, puesto que los amigos, parientes y paisanos españoles más cercanos solían colaborar con una contribución económica. Si esto no era posible, en última instancia las instituciones intervenían.

Una fórmula habitual de ayuda entre inmigrantes para lograr el dinero del pasaje consistió en la organización de suscripciones ${ }^{84}$. Esta práctica podía involucrar la acción de una pequeña comunidad conformada horizontalmente, por lo general la más cercana a la vida cotidiana del inmigrante, o también la acción de las asociaciones de la colonia, en tanto instituciones organizadoras (con una cobertura mayor y a menudo con mejores resultados). Es decir, era un fenómeno que envolvía al conjunto de las sociabilidades de inmigrantes, ya fuera de un modo informal (suscripciones vecinales, familiares, de amigos o de compañeros de trabajo) o en el marco del asociacionismo formalmente instituido. Los componentes aportaban una ayuda económica al tiempo que se comprometían a buscar la misma colaboración entre sus conocidos.

\section{CONCLUSIÓN}

La repatriación asistida por el Estado, tal y como fue concebida en el artículo 46 de la Ley de Emigración de 1907, demostró ser un recurso ineficaz y de una complicada puesta en práctica, debido a la imprecisión con la que fueron redactadas sus principales medidas. Para empezar, el cálculo del veinte por ciento de los emigrantes trasladados a la ida en vapores trasatlánticos era

84 GIL LÁZARO, 2008: 270-279. 
a todas luces inviable por cuanto el concepto mismo de «emigrante» no aparecía especificado de forma clara en las listas de las navieras, las cuales clasificaban a los pasajeros tan solo por clases. La tradicional identificación de los pasajeros de tercera clase como la «clase emigrante» en realidad daba a las empresas una amplia discrecionalidad ante los acuerdos con los consulados sobre el número de pasajes subsidiados. Por otro lado, el hecho de que las normas solo contemplaran el pago de medio pasaje sometió a las instituciones gestoras a una perpetua escasez de medios con los cuales sufragar las repatriaciones. A esto se añadió que las instancias económicas en los peores momentos de crisis, como es el caso del Tesoro del Emigrante a principios de 1930, no contaran con una dotación propia en los presupuestos del Estado sino que ataran sus destinos, de nuevo, al rumbo de los asuntos migratorios (multas, impuestos sobre el tonelaje de los buques o sobre la carga total del pasaje, donaciones, etc.). Todo ello hace pensar que el retorno asistido masivo no estaba en modo alguno en la mente de los hacedores de esta ley.

En efecto, una ley redactada en el momento álgido de salidas hacia América fijó su atención en los problemas que podía causar la salida, pero no tuvo en cuenta en ninguno de sus enunciados tutelares la protección de los inmigrantes frente a las coyunturas de crisis económicas o políticas en los países de acogida. El fin del ciclo migratorio al inicio de la década de 1930 demostró la inviabilidad de los postulados legales ratificados en 1924, aún después de la crisis de posguerra.

Sin embargo, un buen número de repatriaciones se llevaron a cabo. A falta de datos cuantitativos globales, la importancia del proceso para las instancias oficiales encargadas de los asuntos migratorios se ha podido medir a partir de la proliferación de órdenes y decretos expedidos en los casi treinta años que contempla este estudio; en la preocupación manifiesta con que asumieron la gestión de la repatriación diversas instancias - los consulados y las asociaciones migratorias - y en las miles de solicitudes de individuos a las que se dio curso legal en las oficinas consulares. El desfase entre el alto número de solicitudes recibidas y el bajo porcentaje de pasajes concedidos demuestra que los mecanismos legales y los recursos económicos disponibles no fueron suficientes para asegurar la tutela que el Estado español pretendía ejercer sobre el conjunto de los emigrantes españoles.

$\mathrm{Al}$ final, las repatriaciones pudieron efectuarse sobre todo gracias a la actitud proactiva de las instituciones privadas y de la red primaria de los inmigrantes. En la segunda parte del texto hemos tratado de mostrar cómo la interacción entre las estrategias personales de los inmigrantes, con la red densa de asociaciones de los grupos migratorios, y la función cohesiva y mediadora de la burocracia consular, configura una respuesta más plausible a los interrogantes de la repatriación que la acción tutelar del Estado. A lo largo de las décadas que aquí se examinan, pero especialmente durante el decenio de 1920 
y el primer lustro de la siguiente, buena parte del quehacer de la dirección de los centros y sociedades españolas en América estuvo estrechamente relacionado con los consulados para conseguir pasajes subsidiados para los españoles en situación de indigencia o enfermedad. El afán repatriador de las asociaciones asistenciales, mutualistas o benéficas, pone de manifiesto, una vez más, la fortaleza de los vínculos personales y las redes sociales en el proceso migratorio - incluido en este el retorno al lugar de origen-, y la interlocución constante, no exenta de tensiones, con las autoridades migratorias, las empresas navieras y el Estado.

\section{BIBLIOGRAFÍA}

Aróstegui, J., «La emigración en los años treinta», en Vives, Pedro, Vega, Pepa y Jesús Oyamburu (coords.), Historia general de la emigración española a Iberoamérica, 2 vols., Madrid, Historia 16, 1992: 435-459.

Badía Malagrida, Carlos, Ideario de la Colonia Española. Su organización y su programa, México, Talleres Tipográficos Don Quijote, 1921.

Cuesta Bustillo, Josefina, «Los retornos: sueño, horizonte, destino y mito», en Alted Vigil, Alicia y Almudena Asenjo (coords.), De la España que emigra a la España que acoge, Madrid, Fundación F. Largo Caballero, 2006: 380-407.

Devoto, Fernando, Historia de la inmigración a Argentina, Buenos Aires, Editorial Sudamericana, 2003.

Devoto, Fernando, «Para una historia de las migraciones españolas e italianas a las regiones americanas sudatlánticas», Carmagnani, Marcello, Hernández Chávez, Alicia y Rugiero Romano (coords.), Para una historia de América III. Los nudos (2), México, Fondo de Cultura Económica, Fideicomiso Historia de las Américas, 1999.

Durán, José Antonio, «Repatriación, emigración temporal y retornos de larga duración», en Vives, Pedro, Vega, Pepa y Jesús Oyamburu (coords.), Historia general de la emigración española a Iberoamérica, 2 vols., Madrid, Historia 16, 1992: 409-425.

Erice, Francisco, «Retorno y retornados de la emigración a América: el caso de Asturias», en Cuesta Bustillo, Josefina (coords.), Retornos. De exilios y migraciones, Madrid, Fundación F. Largo Caballero, 2000: 39-73.

Espuny Tomás, María Jesús, Torres Paz, Olga, García González, Guillermo y José Cabañate Pérez, Esquemas de historia del derecho y de las instituciones laborales, Valencia, Tirant lo Blanch, 2011.

Frid de Silverstein, Carina, «Mobilidade trasatlántica e circuítos migratorios: perspectivas analíticas e problemas metodolóxicos das migracións de retorno dos españóis dende Arxentina (1880-1939)», Estudos Migratorios, 11-12 (Santiago, 2001): 53-72. 
Gil Lázaro, Alicia, Billete de repatriación. El retorno subvencionado de españoles entre la Revolución y los años treinta, Tesis doctoral, México, El Colegio de México, 2008.

Gil Lázaro, Alicia, «La repatriación gratuita de inmigrantes españoles durante la Revolución mexicana», Historia Mexicana, LX/2, 238 (México, 2010): 1001-1057.

Gil Lázaro, Alicia, «Prácticas mutualistas y discurso caritativo. Un análisis de la labor asistencial de la Sociedad de Beneficencia Española de México (19101936)», Historia social, 70 (Valencia, 2011): 81-105.

González Martínez, Elda, «Tres inmigrantes, cuatro centros, un periódico... las asociaciones españolas en Brasil», Blanco Rodríguez, Juan Andrés (coord.), El asociacionismo en la emigración española a América, Salamanca, UNED, 2008: 365-387.

Hernández García, Julio, «Acerca de la repatriación de españoles de Argentina y Uruguay (circa 1930-1932)», Jornadas de Estudios Canarias-América, Santa Cruz de Tenerife, Confederación Española de Cajas de Ahorro, 1990: 99-115.

Hernández García, Julio y Manuel Hernández González, «Cuba, crisis económica y repatriación», Anuario de Estudios Atlánticos, 39 (Madrid, 1993): 583-607.

Hernández Sandoica, María Elena, «La Compañía Trasatlántica Española: una dimensión ultramarina del capitalismo español», Historia Contemporánea, 2 (Madrid, 1989): 119-164.

Inspección General de Emigración, Compilación de las disposiciones dictadas sobre emigración, tomos I, II y III, Madrid, 1932.

Llordén Miñambres, Moisés, «El asociacionismo de los inmigrantes españoles en América, proceso formativo y manifestaciones más notables», Blanco Rodríguez, Juan Andrés (coord.), El asociacionismo en la emigración española a América, Salamanca, UNED, 2008: 51-90.

Maluquer de Motes, Jordi, «La incidencia de la Gran Depresión y de la Guerra Civil en la población de España (1931-1940)», Revista de Demografía Histórica, XXV/II, segunda época (Madrid, 2007): 131-166.

Marsal, Juan Francisco, Hacer la América. Autobiografía de un inmigrante español en la Argentina, Buenos Aires, Editorial del Instituto [Di Tella], 1969.

Naranjo, Consuelo y Alfredo Moreno, «La repatriación forzosa y las crisis económicas cubanas: 1921-1933», Arbor, 536-537 (Madrid, 1990): 203-230.

Núñez Seixas, Xosé Manoel, «Emigración de retorno y cambio social en la Península Ibérica: algunas observaciones teóricas en perspectiva comparada», Migraciones \& Exilios, 1 (Madrid, 2000): 27-66.

Núñez Seixas, Xosé Manoel, «Visible and Invisible Remittances: Some Notes on Trasatlantic Return Migration and its Effects on Iberian Societies, 1850-1950», Przeglad Polonijny, 115, 31/1 (Varsovia, 2005): 117-142.

Pérez-Prendes, José María, El marco legal de la emigración española en el Constitucionalismo. (Un estudio histórico-jurídico), Gijón, Archivo de Indianos, 1992. 
Sánchez Alonso, Blanca, Las causas de la emigración española, 1880-1930, Madrid, Alianza, 1995.

Sánchez Alonso, Blanca, «La época de las grandes migraciones: desde mediados del siglo XIX hasta 1930», Mediterráneo económico: procesos migratorios, economía y personas, 1 (Almería, 2002): 19-32.

Sánchez Rivas, Francisco, «La emigración española a los países americanos», Boletín de emigración, tomo II, 1, 1930.

Tabanera, Nuria, Ilusiones y desencuentros: la acción diplomática republicana en Hispanoamérica (1931-1939), Madrid, Fundación Centro Español de Estudios de América Latina, 1993: 97-109.

Tabanera, Nuria, «La política migratoria española entre la dictadura y la República (1923-1936): tutela y repatriación del emigrante español en América Latina», Exils et Migrations Ibériques au XXe siécle, 7 (París, 1999): 73-93.

Yáñez Gallardo, César, La emigración española a América (siglos XIX y XX). Dimensión y características cuantitativas, Gijón, Archivo de Indianos, 1994.

Vázquez González, Alejandro, «La emigración gallega. Migrantes, transporte y remesas», Sánchez-Albornoz, Nicolás (coord.), Españoles hacia América: la emigración en masa, 1880-1930, Madrid, Alianza Editorial, 1988.

Yanes Mesa, Julio Antonio, «La repatriación de los emigrados canarios tras el hundimiento del sector azucarero cubano, 1920-1935», Anales de Historia contemporánea, 25 (Murcia, 2009): 373-387.

Recibido: 04/09/2012

Aprobado: 19/04/2013 